\title{
Histological Subtypes \& Staging of Post-Chemotherapy Wilms Tumor According to SIOP 2001 Protocol: Study at the Children's Hospital, Lahore
}

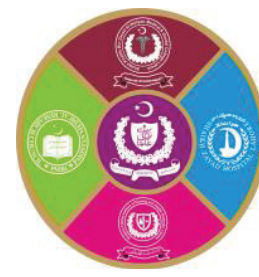

${ }^{1}$ Fariha Sahrish, ${ }^{2}$ Abeera Assad Rasool, ${ }^{2}$ Zonaira Rathore, ${ }^{2}$ Mahvish Hussain, ${ }^{2}$ Fizza Waqar, ${ }^{2}$ Samina Zaman

${ }^{1}$ Department of Histopathology, Azra Naheed Medical College, Lahore

${ }^{2}$ Department of Histopathology, Children's Hospital, Lahore

\begin{abstract}
Introduction: Pediatric renal tumors constitute 7 to $8 \%$ of pediatric solid malignancies and most common is Wilms tumor. It usually presents as unilateral mass with sporadic and familial associations. It is currently treated by NWTS and SIOP protocols worldwide. In our hospital setup we follow SIOP 2001 protocol to subcategorize different histological subtypes and staging of Wilms tumor after completing four cycles of chemotherapy.

Aims \& Objectives: To determine the frequency of histological subtypes of Wilms tumor (WT) in post chemotherapy nephrectomy specimens

Place and duration of study: Histopathology Section of Pathology Department, Children's Hospital and Institute of Child Health Lahore from January 2015 to June 2018.

Material \& Methods: Ninety-three radical nephrectomy specimens of different histological subtypes i.e. Wilms Tumor (WT) consisting of blastemal predominant (BP), epithelial predominant (EP), stromal (ST), mixed (MT), regressive (RP), completely necrotic $(\mathrm{CN})$ and diffuse anaplastic (DA) were analyzed. Risk categorization and staging proposed by SIOP 2001 was appraised. Data analysis was done using SPSS version 23.

Results: A total of 93 cases were included in the present study. Mean age of children recorded was 42 months with male predominance. Mean tumor size after chemotherapy was $7.25 \mathrm{~cm}$. Majority cases were observed on the right side. Regarding the histological subtype there was a predominant group of MT while least observed was DA. Based on subtypes and necrosis, majority of WT were of intermediate risk (IR) and stage I tumors.

Conclusion: Majority of pretreated cases $(n=80,85.1 \%)$ were stage 1 tumors. Commonest histological subtype is MT followed by RP, CN, EP, BP, ST and DA.
\end{abstract}

Key words: Wilms tumor (WT), (SIOP staging) Internal Society of Pediatric Oncology) National Wilms Tumor Study Group (NWTS), Post chemotherapy WT.

\section{INTRODUCTION}

$\mathrm{P}$ ediatric renal tumors comprise 7 to $8 \%$ pediatric solid malignancies in first 15 years of life. Most common renal tumor is Wilms tumor (WT), also known as nephroblastoma $(\mathrm{N})$ which accounts for $85 \%$ of cases. It usually presents as palpable abdominal mass noticed by mother. ${ }^{1,2}$ Median age of children is 3-4 years. ${ }^{3}$ WT mostly presents as unilateral renal mass but 5-10\% cases are bilateral. ${ }^{4}$ WT1 gene located on chromosome $11 \mathrm{p} 13$ is associated with both familial and sporadic cases. Vast majority of WT are sporadic and only $10 \%$ are familial. Familial WT are associated with Beckwith Wiedemann Syndrome, Denys Drash syndrome and WAGR syndrome. No specific risk factor contributing towards WT has been identified uptil now. ${ }^{1,3,4}$
Grossly most of the cases of WT are unicentric, whereas 5\% WT are multicentric. ${ }^{5}$ Undifferentiated blastemal element, epithelial component and stromal component constitute classic WT. The potential precursor of WT are nephrogenic rests which are embryonic stem cells and are of perilobar and intralobar types. ${ }^{3,5}$

WT is managed according to two protocols, National Wilms Tumor Study Group (NWTS) and International Society of Pediatric Oncology (SIOP) which are established over years of multicenter trials. These groups have enormous contributions towards the management and excellent prognosis of patients with WT. $3,4,6,7,8$

The NWTS, established in 1969, completed 5 sequential trials from NWTS-1 to NWTS-5. It endorses the diagnosis of WT on radiological examination followed by core biopsy and prompt radical nephrectomy. ${ }^{2}$ Currently, NWTS-5 is 
analyzing genetic prognostic factors such as loss of heterozygosity on chromosome $1 \mathrm{p}$ and $16 \mathrm{q} .{ }^{9}$

Shortly after NWTS, SIOP trials were started in 1971 and evolved from the SIOP 1 to SIOP 9 (19712001). It advocates prophylactic chemotherapy after initial diagnosis made on core biopsy. After cessation of chemotherapy course, it endorses radical nephrectomy in unilateral cases and partial nephrectomy in bilateral cases..$^{10,11}$

The histological classification of WT differs in NWTS and SIOP 2001 due to preoperative chemotherapy. Accurate histological subtyping and staging of WT is very important in further management and prognosis of patient. ${ }^{1,2}$

According to NWTS, histology groups are divided on the basis of presence and absence of anaplasia in three groups. The favorable histology WT is cystic partially differentiated nephroblastoma (CPDN), standard risk (SR) histology group includes nonanaplastic WT and its variants and high risk (HR) diffuse anaplasia (DA). According to the SIOP WT 2001 classification the subtypes are classified on the basis of percentage of necrosis, presence of viable tumor, presence and absence of regressive changes and presence of focal and diffuse anaplasia. Low risk (LR) include completely necrotic (CN), intermediate risk (IR) include Epithelial predominant (EP), Stromal Type (ST), Mixed type (MT), Regressive predominant (RP), Focal Anaplasia (FA) and high risk (HR) tumors include Blastemal predominant (BP) and diffuse anaplasia (DA). ${ }^{3,10,11,12}$ In our centre we are following SIOP 2001 protocol.

The present study is carried out to determine the frequency and morphological features of WT according to SIOP 2001 protocol as our centre is following their protocol.

\section{MATERIAL AND METHODS}

The present study is a cross-sectional study approved by Ethical Review Board vide its letter No. 02/173/17 dated 01/02/2017 and carried out at the Histopathology Department of Children's Hospital and Institute of Child Health Lahore from January 2015 to June 2018.

Ninety-three radical nephrectomy specimens of children between $0-15$ years of age in both genders of biopsy proven cases of WT tumor were included. Partial nephrectomy specimens and blocks received for review were excluded.

Different histological subtypes i.e. WT consisting of blastemal, epithelial, stromal, mixed, regressive, completely necrotic and anaplastic were analyzed.
Risk categorization and staging proposed by SIOP 2001 was appraised.

Radical nephrectomy specimens were meticulously sectioned as per protocol of American College of Pathologists. Specimen size, areas of suspected tumor rupture, capsular and perinephric invasion, sectioning of distal end of ureter, renal vein and artery for tumor metastasis and tumor thrombus was noted prior to opening of specimen at the department. Sectioning of tumor at one centimeter was done and assessment of necrotic areas, viable tumor areas and its relation to the normal kidney, capsule, renal hilum and renal sinus was done grossly. Additional sections from the tumor and normal kidney were taken to assess nephrogenic rests. Tissue slices were processed in the automatic tissue processor for 16 hours overnight dehydrated with ethyl alcohol, cleared by xylene, impregnated with paraffin wax and later on tissue blocks were made. Hematoxylin and eosin stains were done.

\section{Statistical analysis:}

Data analysis was done on SPSS (Statistical Packages of Social Sciences) version 23. Qualitative variables like age, gender, laterality, histological subtypes and staging were summarized as frequencies and percentages. No statistical association is determined between any variables.

\section{RESULTS}

A total of 93 cases were included in this study. The main clinical features of the study are presented in Table-1.

\begin{tabular}{|c|c|c|}
\hline \multicolumn{3}{|c|}{ Age at diagnosis } \\
\hline Mean & \multicolumn{2}{|c|}{3.6 years } \\
\hline Minimum age & \multicolumn{2}{|c|}{6 months } \\
\hline Maximum age & \multicolumn{2}{|c|}{15 years } \\
\hline & Number (n) & Percentage (\%) \\
\hline 0 to 3 years & 52 & 55.9 \\
\hline 4 to 6 years & 30 & 32.3 \\
\hline 7 to 9 years & 8 & 8.6 \\
\hline 10 to 12 years & 2 & 2.2 \\
\hline More than 12 years & 1 & 1.1 \\
\hline \multicolumn{3}{|l|}{ Gender } \\
\hline Male & 52 & 55.9 \\
\hline Female & 41 & 44.1 \\
\hline \multicolumn{3}{|l|}{ Laterality } \\
\hline Right & 52 & 55.9 \\
\hline Left & 37 & 39.8 \\
\hline \multicolumn{3}{|c|}{ Tumor size in $\mathrm{cm}$} \\
\hline Mean tumor size & \multicolumn{2}{|c|}{7.25} \\
\hline Minimum tumor size & \multicolumn{2}{|c|}{1.5} \\
\hline Maximum tumor size & \multicolumn{2}{|r|}{16} \\
\hline
\end{tabular}

Table-1: Principal clinicopathological features of Wilms Tumor 
Majority of the patients were seen in first 3 years of age with a male predominance $n=52(55.9 \%)$. Most cases were in right kidney $(\mathrm{n}=52,55.9 \%)$ with mean tumor size $7.25 \mathrm{~cm}$. However, largest tumor size observed was $16 \mathrm{~cm}$ after chemotherapy (Fig-1).

Regarding the histological subtype the commonest was MT ( $\mathrm{n}=41,44.1 \%)$, followed by RP $(\mathrm{n}=16$, 17.2\%). There were equal number of $\mathrm{EP}$ and $\mathrm{CN}$ $(\mathrm{n}=12,12.9 \%)$. In addition, 9 cases $(9.7 \%)$ were of BP, 2 cases $(2.2 \%)$ of ST whereas only one case $(1.1 \%)$ was of DA.

Considering necrosis, majority of the tumors $(n=65$, $69.9 \%$ ) showed less than $66 \%$ necrosis and 28 cases (30.1\%) showed more than $66 \%$ necrosis. On the basis of histological subtypes and necrosis, (76.3\%) cases belonged to IR, whereas $12.9 \%$ cases were of LR and $10.8 \%$ cases were of HR according to SIOP staging protocol.

In the present study majority of the cases were limited to kidney, only in 7 cases hilum was involved. Capsule was involved in 2 cases and similar number of cases showed tumor thrombi in renal vein whereas in a single case inferior vena cava was involved by tumor thrombus clinically. Distal end of ureter, perinephric fat infiltration and nephrogenic rests were seen in one case each.

We received lymph nodes in 28 cases, which were all negative for metastatic disease. 80 cases $(86 \%)$ had stage I, 11 cases $(11.8 \%)$ had stage II and 2 cases $(2.2 \%)$ had stage III.

The pathological features concerning histological subtypes, staging and largest tumor size is presented in Table-2.

\begin{tabular}{|l|c|c|c|c|}
\hline $\begin{array}{c}\text { Histological } \\
\text { subtypes }\end{array}$ & $\begin{array}{c}\text { Stage I } \\
\text { n (\%) }\end{array}$ & $\begin{array}{c}\text { Stage II } \\
\text { n (\%) }\end{array}$ & $\begin{array}{c}\text { Stage III } \\
\text { n (\%) }\end{array}$ & $\begin{array}{c}\text { Largest } \\
\text { Tumor } \\
\text { size(cm) }\end{array}$ \\
\hline Mixed type & $34(36.5)$ & $6(6.4)$ & $1(1.07)$ & 16 \\
\hline $\begin{array}{l}\text { Regressive } \\
\text { predominant }\end{array}$ & $14(15)$ & $2(2.1)$ & $0(0)$ & 10 \\
\hline $\begin{array}{l}\text { Completely } \\
\text { necrotic }\end{array}$ & $11(11.8)$ & $1(1.07)$ & $0(0)$ & 14 \\
\hline $\begin{array}{l}\text { Epithelial } \\
\text { predominant }\end{array}$ & $10(10.7)$ & $2(2.1)$ & $0(0)$ & 11 \\
\hline $\begin{array}{l}\text { Blastemal } \\
\text { predominant }\end{array}$ & $8(8.6)$ & $0(0)$ & $1(1.07)$ & 14 \\
\hline $\begin{array}{l}\text { Stromal } \\
\text { predominant }\end{array}$ & $2(2.1)$ & $0(0)$ & $0(0)$ & 6 \\
\hline $\begin{array}{l}\text { Anaplasia }- \\
\text { diffuse }\end{array}$ & $1(1.07)$ & $0(0)$ & $0(0)$ & 10 \\
\hline Total No. & $\mathbf{8 0 ~ ( 7 9 )}$ & $\mathbf{1 1 ( 1 1 . 8 )}$ & $\mathbf{2 ~ ( 2 . 1 )}$ & $\mathbf{8 1}$ \\
\hline
\end{tabular}

Table-2: Histological subtypes, staging and largest tumor size according to SIOP 2001.
Concerning the stage distribution as shown in Table-2 the greater proportion of cases were of stage I with predominant histological type MT.

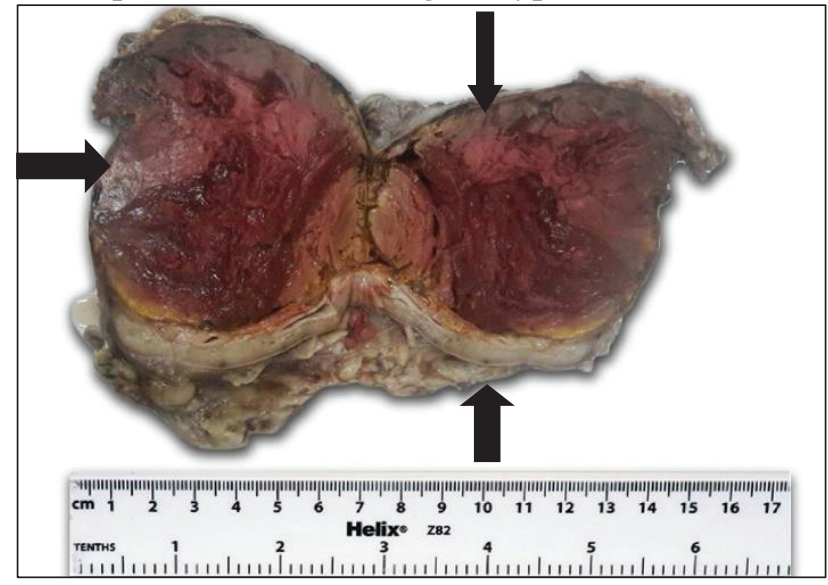

Fig-1:A post chemotherapy bivalved kidney shows a well circumscribed tumor with mahogany cut surface (down \& right arrow), and periphery shows thin rim of normal renal parenchyma (up arrow)

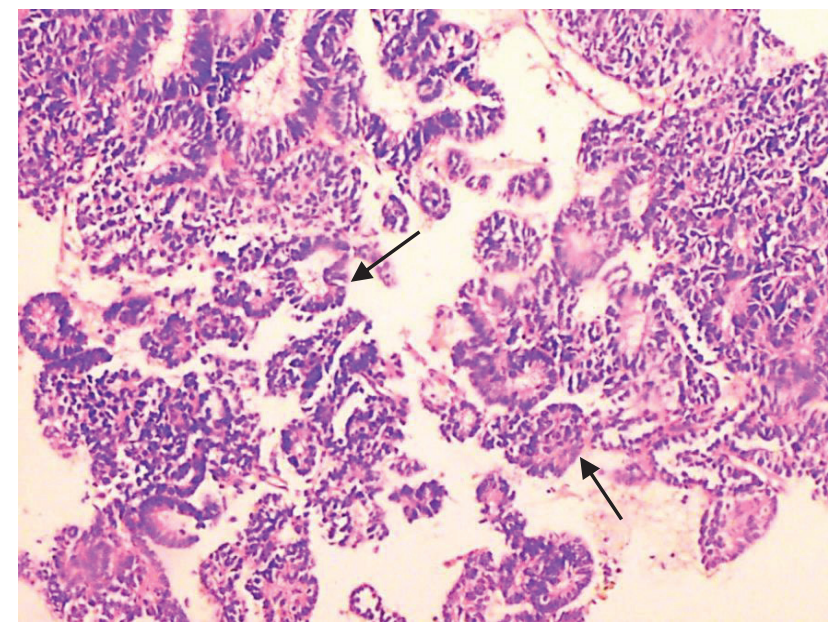

Fig-2: Photomicrograph of H\&E staining showing neoplastic tubules (arrows) in residual Wilms Tumor X 20

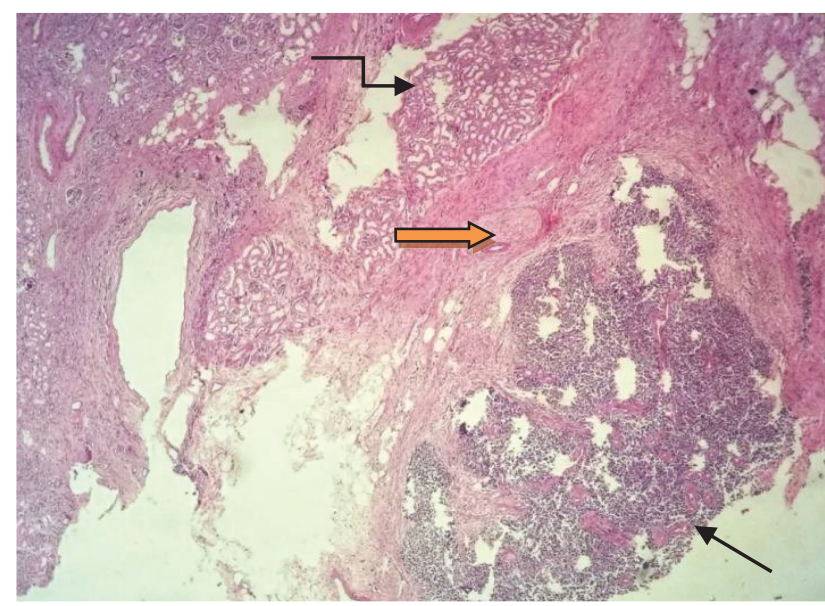

Fig-3: Photomicrograph of H\&E staining showing a renal hilum (right arrow), involved by Wilms Tumor (arrow) adjacent normal kidney parenchyma (elbow arrow) X 20 


\section{DISCUSSION}

The prevalence of malignant pediatric tumors is remarkably higher in the developing countries as compared to the developed nations. In developing countries, pediatric malignancies prevalence is reported as $4.38 \%$ to $12.6 \%$ as compared to $2 \%$ in developed countries. ${ }^{13}$ It affects approximately one child in every 10,000 children, worldwide before the age of 15 years. $^{4}$ According to World Health Organization (WHO), International Incidence of Childhood Cancer, the Incidence-age specific rate per million in Pakistan and India is 3.6 and 4.4 respectively. ${ }^{14}$ According to Annual Cancer Registry Report by Shaukat Khanum Cancer Hospital there were 27 cases of WT, NOS in 2018 in Pakistani population. ${ }^{15}$

We received 93 cases of post chemotherapy WT in approximately 3.5 years with the mean age of 3.5 years (Table-1). Similarly, Guruprasad et al. observed the mean age of 3.3 years in the duration of 6 years in Indian population. ${ }^{16}$ Mazumder et al. a peak age of approximately 4 years in a 20 patients cross sectional study, ${ }^{17}$ Anwar et al. had the observation of mean age of WT at the age of 3 years ${ }^{18}$ whereas Onuigbo noticed the peak age of WT lies between 2 years to approximately 5 years. ${ }^{19}$ Regarding sex, we had majority of the male patients (Table-1). This observation was similar to Gruparasad et al,${ }^{16}$ Mazumder et al,${ }^{17}$ Anwar et al, ${ }^{18}$ Onuigbo et al, ${ }^{19}$ Weirich et $\mathrm{al}^{11}$ and Sayed et $\mathrm{al}^{21}$ whereas Shende SA showed female preponderance. ${ }^{22}$

There was a predominately right sided renal involvement in our index study (Table-1). Similar to Mazumder et al, ${ }^{17}$ Anwar et al, ${ }^{18}$ Onuigbo et al ${ }^{19}$ and Basu et al. ${ }^{20}$ However, Weirich et $\mathrm{al}^{11}$ and Sayed et $\mathrm{al}^{21}$ observed predominantly left renal involvement. Bilateral WT was reported by Pianezza et $\mathrm{al}^{23}$ Gruparasad et $a{ }^{16}{ }^{16}$ Anwar et $\mathrm{al}^{18}$ and Sayed et $\mathrm{al}^{21}$ whereas bilateral WT was excluded in our study.

Regarding the histological subtype, there was a marked predominance of MT in our study and only $12 \%$ of the total cases were CN (Table-2). Similar to Mazumder et al who also observed predominantly tumors of MT in their study. ${ }^{17}$ Sayed et al. had the observation that most of the cases were of nonanaplastic type and had the MT histological picture followed by EP type. ${ }^{21}$ However, Vujanic et al. showed that in 258 of the total pretreated nephrectomy specimens, majority of the cases were of RP followed by MT. ${ }^{24}$

Bocon-Gibond et al. showed majority as $\mathrm{CN}$ in their study. ${ }^{12}$ In contrast, Vujanic et al studied 195 pre treated nephrectomy specimens and he noticed a major chunk of MT and $\mathrm{CN}$ which was seen in $17 \%$ of the cases. ${ }^{25}$

In our study majority were of Stage I tumors (Table2) similar to Sayed et al, ${ }^{21}$ Vujanic et $\mathrm{al}^{24}$ and Hung IJ et al. ${ }^{27}$ In contrast, Faranoush et al. observed slight predominance of Stage II tumors ${ }^{26}$ where as, Guruprasad et $\mathrm{al}^{16}$ and Anwar et $\mathrm{al}^{18}$ observed majority of the patients were in stage III.

Verschuur AC et al showed EP and ST showed excellent clinical outcomes which was beyond the scope of our case study. ${ }^{28}$

\section{CONCLUSION}

Following SIOP 2001 protocol the commonest histological type is mixed subtype which has Intermediate risk. Majority of our tumors were of Stage I tumors.

\section{REFERENCES}

1. Vujanić GM and Sandstedt B. The pathology of Wilms' tumour (WT): the International Society of Paediatric Oncology approach. J ClinPathol 2010; 63(2):102-9.

2. Davidoff AM. Wilms Tumor. AdvPediatr. 2012; 59(1):247-67.

3. Varan A. Wilms' Tumor in Children: An Overview. Nephron ClinPract 2008; 108:83-90.

4. Charlton J, Irtan S, Bergeron C, Pritchard-Jones K. Bilateral Wilms tumour: a review of clinical and molecular features. Expert Rev Mol Med.2017;19:e8

5. Friedman AD. Wilms tumorPediatrics in Review 2013; 34(7):328-30.

6. Bhatnagar S. Management of Wilms tumor: NWTS vs SIOP. Journal of Indian Association of Pediatric Surgeons. 2009; 14(1):6-14.

7. Lopes RI, Lorenzo A. Recent advances in the management of Wilms' tumor. F1000Res.2017;6:670

8. Brok J, Lopez-Yurda M, Tinteren HV, Treger TD, Furtwängler R, Graf N, Bergeron C, Heuvel-Eibrink MMvd, Pritchard-Jones K Olsen OE, Camargo B, Verschuur A, Spreafico F. Relapse of Wilms' tumour and detection methods: a retrospective analysis of the 2001 Renal Tumour Study Group-International Society of Paediatric Oncology Wilms' tumour protocol database. Lancet Oncol.2018;19(8):1072-81

9. Grundy PE, Breslow NE, Li S, Perlman E, Beckwith JB, Ritchey ML, Shamberger RC, Haase GM, D'Angio GJ, Donaldson M, Coppes MJ, Malogolowkin M, Shearer P, Thomas PR, Macklis R, Tomlinson G, Huff V, Green DM; National Wilms Tumor Study Group. Loss of heterozygosity for chromosomes $1 p$ and $16 q$ is an adverse prognostic factor in favorable-histology Wilms tumor: a report from the National Wilms Tumor Study Group. J ClinOncol. 2005; 10;23(29):7312-21.

10. Metzger M and Dome J. Current Therapy for Wilms Tumor. Pediatr. Oncol. 2005; 10:815-26. 
11. Weirich A, Leuschner I, Harms D, Vujanic GM, Troger J, Abel U, Graf N, Schmidt D, Ludwig R and Voute PA. Clinical impact of histologic subtypes in localized non-anaplastic nephroblastoma treated according to the trial and study SIOP-9/GPOH. Annals of Oncology. 2001; 12:311-9.

12. Boccon-Gibod L, Rey A, Sandstedt B, Delemarre J,Harms D, Vujanic G, De Kraker J, Weirich A, and Tournade MF. Complete necrosis induced by preoperative chemotherapy in Wilms tumor as an indicator of low risk: Report of the International Society of Paediatric Oncology (SIOP) Nephroblastoma. Medical and Pediatric Oncology 2000; 34:183-190.

13. Shah SH, Soomro IN, Siddiqui MS, Pervez S, and Hassan SH. Immunohistochemical evaluation of small round cell tumors of childhood. J Pak Med Assoc. 1999; 49(4). 87-9.

14. Cunningham ME, Klug TD, Nuchtern JG, Chintagumpala MM, Venkatramani R, Lubega J, Mathuria BJ. Global Disparities in Wilms Tumor. J Surg Res. 2019; 247(832):34-51.

15. Yousaf A, Mahmood S, Faraz R, Quader A, Asif H, Atif A, Nadeem L, Parveen N, Tanveer R, Hussain A, Badar F.Annual Cancer Registry Report-2018, of The ShaukatKhanum Memorial Cancer Hospital \& Research Center, Pakistan. 2016, 1-21.

16. Guruprasad B, Rohan B, Kavitha S, Madhumathi DS, Lokanath D and Appaji L. Wilms'Tumor: Single Centre Retrospective Study from South India Indian J SurgOncol 2013; 4(3):301-304.

17. Mazumder M, Islam A, Farooq N, Zaman M. Clinicopathological Profile of Wilms' Tumour in Children. J BanagladeshCollPhysSurg 2014; 32:5-8

18. Anwar S, Faizan M, Khan S, Tallat N Saleem M, Khalid A, Qaiser, Qureshi A, Ali AS, Rathore A. A Five Year Experience of Wilms Tumor at a tertiary care centre, where we stand, a developing country perspective. P J M H S 2017; 11(4):1263-6.

19. Onuigbo W. Comparative Approach to the Epidemiology of Wilm's Tumor: Archives in Cancer Research. 2016; 4.10.21767/2254-6081.100048.

20. Basu K, Chattopadhyay S, Das S, Basu N, Chatterjee $\mathrm{S}$, Das S. Role of FNAC in Wilms' Tumoraninterim report, J AssocPediatr, 2001;6:130-3.

21. Sayed HAR, Ali AM, Hamza HM, and Abdalla MA. Long-term Follow-up of Infantile Wilms Tumor Treated According to International Society of Pediatric Oncology Protocol: Seven Years' Followup. Urology 2011; 77(2):446-5.

22. Shende A, Sathe PA. Clinicopathologic analysis of Wilms' tumor - A retrospective study of 35 cases over 10 years. Ann Pathol Lab Med. 2018; 5(2):A151-157.

23. Pianezza ML, Rubin S, Bass J, Chou S, Pike JG, Leonard MP. Wilms tumor at the Children's Hospital of Eastern Ontario. Can J Urol. 2004, 11: 2151-6.

24. Vujanić GM, D'Hooghe E, Popov SD, Sebire NJ, Kelsey A. The effect of preoperative chemotherapy on histological subtyping and staging of Wilms tumors: The United Kingdom Children's Cancer Study Group (UKCCSG) Wilms tumor trial 3 (UKW3) experience. Pediatr Blood Cancer. 2019; 66(3):27549.

25. Vujanić GM, Kelsey A, Mitchell C, Shannon RS, and Gornall P, "The role of biopsy in the diagnosis of renal tumors of childhood: Results of the UKCCSG Wilms Tumor Study 3. Med PediatrOncol 2003; 40(1):18-22.

26. Faranoush M, Bahoush GR, Mehrvar A, Hejazi S, Vossough P, Hedayatiasl AA, Rahiminejad MS, Seighali F, Ghorbani R and Ehsani MA. Wilm's tumor: Epidemiology and Survival. Research Journal of Biological Sciences 2009; 4 (1): 86-89.

27. Hung IJ, Yang CP et al, Epidemiology, clinical feature and treatment outcome of Wilms' Tumor in Taiwan: a report from Taiwan pediatric oncology group. J Formos Med Assoc, 2004; 103:104-11.

28. Verschuur AC, Vujanic GM, Van Tinteren H, Jones KP, De Kraker J, Sandstedt B. Stromal and epithelial predominant Wilms Tumours have an excellent outcome: The SIOP 9301 experience. Pediatr Blood Cancer. 2010 Aug; 55(2):233-8.

\section{The Authors:}

Dr. Fariha Sahrish

Senior Demonstrator,

Department of Histopathology,

Azra Naheed Medical College Lahore.

Dr. Abeera Assad Rasool

Women Medical Officer,

Department of Histopathology,

Children's Hospital, Lahore.

Dr. Zonaira Rathore

Assistant Professor,

Department of Histopathology,

Children's Hospital, Lahore.

Dr. Mahvish Hussain

Assistant Professor,

Department of Histopathology,

Children's Hospital, Lahore.

Dr. Fizza Waqar

Women Medical Officer,

Department of Histopathology,

Children's Hospital, Lahore.

Prof. Samina Zaman

Department of Histopathology,

Children's Hospital, Lahore.

\section{Corresponding Author:}

Dr. Fariha Sahrish

Senior Demonstrator,

Azra Naheed Medical College, Lahore.

E-mail: awan.fariha44@gmail.com 